\title{
Otimização do tamanho de população sob acasalamento seletivo na seleção assistida por marcadores moleculares ${ }^{1}$
}

\author{
Marcelo Jangarelli², Ricardo Frederico Euclydes ${ }^{3}$
}

\footnotetext{
${ }^{1}$ Fonte de financiamento: CNPq.

2 Doutorando em Genética e Melhoramento - UFV.

${ }^{3}$ Departamento de Zootecnia - UFV, Viçosa, MG.
}

RESUMO - Foram simulados diferentes tamanhos populacionais para estimar os valores fenotípicos na seleção assistida por marcadores para características quantitativas com valores de herdabilidade de 0,10;0,40 e 0,70. Procedeu-se à análise de agrupamento com os desempenhos fenotípicos, cuja finalidade foi obter estruturas de classificação entre as amostras visando à otimização na deteç̧ão de QTL. O sistema de simulação genética (Genesys) foi utilizado para a simulação de três genomas (cada qual com uma única característica cuja distinção estava no valor da herdabilidade) e das populações base e inicial. Cada população inicial foi submetida à seleção assistida por marcadores por 20 gerações consecutivas, em que os genitores selecionados acasalavam-se seletivamente, entre os melhores e os piores. Essa estratégia seletiva de acasalamento mostrou-se eficiente na redução do número de indivíduos requeridos em uma população para mapeamento de QTL. À medida que aumenta a magnitude da herdabilidade, menores tamanhos populacionais são exigidos para manter similaridades nos incrementos fenotípicos. O emprego de amostras com 300, 250 e 200 ou mais indivíduos para as herdabilidades de 0,10; 0,40 e 0,70, respectivamente, é desnecessário, tendo em vista as inferências equivalentes indicadas pelos métodos de otimização de Tocher e da ligação completa, oriundas do sistema de análises estatísticas e genéticas (SAEG).

Palavras-chave: amostragem, análise de agrupamento, herdabilidade, simulação, QTL

\section{Optimization of the population size under selective mating in the selection assisted by molecular markers}

\begin{abstract}
Different population sizes were simulated to estimate the phenotypic values in the selection assisted by markers for quantitative characteristics with heritability values of $0.10,0.40$ and 0.70 . Cluster analysis with the phenotypic performance was carried out aiming at obtaining classification structure among the samples to optimize QTL detection. The genetic simulation system (Genesys) was used for the simulation of three genomes (each one consisting of a single characteristic whose distinction was the value of heritability), and the base and original populations. Each initial population was submitted to selection assisted by markers for 20 consecutive generations, in which selected parents mated selectively among the best and the worst ones. This selective strategy of mating proved itself to be efficient in reducing the number of individuals required in a population for QTL mapping. As the magnitude of heritability increases, lower population sizes are required to maintain similarities in phenotypic increments. The use of samples with 300, 250 and 200 individuals or more for heritabilities of 0.10 , 0.40 and 0.70 , respectively, is unnecessary, because of the equivalent inferences indicated by Tocher optmization and complete linkage methods from the system of statistical and genetic analysis (SAEG).
\end{abstract}

Key Words: cluster analysis, heritability, sampling, simulation, QTL

\section{Introdução}

A genética molecular vem se tornando uma ferramenta auxiliar nos processos de seleção e melhoramento. Ela possibilita a identificação de regiões genômicas associadas a locus de características de importância econômica (Quantitative Trait Loci - QTL), aprimorando os métodos seletivos com o auxílio da seleção assistida por marcadores (Marker Assisted Selection - MAS) (Silva et al., 2009).
O tamanho da população e o tamanho das famílias estão entre os fatores mais importantes para se obterem associações significativas entre marcador e QTL. Esses fatores são referidos como controláveis, podendo ser implementados para otimizar o mapeamento de QTL (Zhu et al., 2001). Segundo Lander \& Botstein (1989), experimentos com maior tamanho amostral podem detectar locus quantitativos de menores efeitos genéticos. Aumentar o tamanho de famílias é mais relevante para otimizar o poder 
de detecção de QTL, em analogia ao aumento do número de famílias (van der Beek et al., 1995; Silva et al., 2005).

De acordo com Lander \& Botstein (1989) e Darvasi \& Soller (1992), a metodologia da genotipagem seletiva é uma estratégia que pode reduzir o número de indivíduos em uma população para manter determinado poder de detecção de QTL. Nessa seleção estratégica os indivíduos presentes nos extremos superior e inferior da distribuição normal do parâmetro avaliado são genotipados, procedendo ao acasalamento entre os selecionados e posicionados nos extremos opostos da distribuição Gaussiana. A ligação marcador e QTL está diretamente relacionada com o número de indivíduos e sua divergência genética. A seleção e o acasalamento seletivo são ferramentas aplicadas para aumentar o poder de detecção de QTL.

O objetivo neste trabalho foi identificar tamanhos populacionais ótimos utilizando a estratégia seletiva de acasalamento na seleção assistida por marcadores, via simulação de dados, utilizando diferentes intensidades de seleção (tamanhos populacionais) de uma população experimental disponível, por meio da estimação dos valores fenotípicos.

\section{Material e Métodos}

Foram utilizados dados simulados pelo sistema de simulação genética Genesys (Genetic System), versão 2009, desenvolvido por Euclydes (1996). Esse sistema, escrito na linguagem de programação FORTRAN, foi desenvolvido para permitir a simulação de genomas complexos e possibilita o estudo de parâmetros genéticos e estatísticos nos processos de seleção, testes de pressuposições, avaliação de metodologias seletivas, entre outras possibilidades.

Foram simulados três genomas hipotéticos, separadamente, cuja distinção estava no valor da herdabilidade da característica. Cada genoma foi constituído de uma característica quantitativa com herdabilidade de 0,10; 0,40 e 0,70 , respectivamente.

Cada genoma proposto estava caracterizado geneticamente: apresentava 958 centiMorgan (cM) de extensão; os marcadores moleculares foram dispostos estrategicamente a cada cinco cM, totalizando 191 marcadores; 200 locus quantitativos (QTL) associados à característica, distribuídos ao longo de 40 cromossomos de tamanho aleatório; os efeitos aditivos dos QTL foram simulados seguindo a distribuição normal dos dados fenotípicos; os locus quantitativos foram dialélicos e não possuíram desvios de dominância e nem epistasia; as frequências gênicas iniciais foram iguais para ambos os sexos; as frequências gênicas iniciais para os marcadores moleculares seguiram distribuição normal, apresentando valores próximos a 0,5 ; os efeitos de ambiente foram simulados conforme a distribuição normal; os dados fenotípicos simulados apresentaram média de 10,00 unidades e desvio-padrão 2,00 unidades.

Para cada estrutura genômica simulada foi construída uma população base composta de 500 machos e 500 fêmeas (1.000 indivíduos), todos heterozigotos, não aparentados. Com os 1.000 descendentes escolhidos aleatoriamente em cada população base, obtidos do cruzamento de 100 machos e 100 fêmeas (uma fêmea/macho), produzindo dez filhos/ fêmea/macho (1.000 indivíduos), formaram-se as populações iniciais. Cada população inicial foi submetida à seleção assistida por marcadores (Marker Assisted Selection MAS) por 20 gerações consecutivas com 20 repetições, visando minimizar os efeitos da flutuação genética. A seleção foi conduzida com a finalidade de incrementar o valor fenotípico.

A partir de cada uma das três populações iniciais, os reprodutores eram selecionados com base nos genótipos de um número de marcadores moleculares que estariam estatisticamente associados à locus quantitativos. A cada geração, os dez machos e as dez fêmeas (uma fêmea/macho) que obtiveram os melhores desempenhos foram acasalados. O número de progênies em cada cruzamento foi dependente do tamanho da população considerada. Esses descendentes formavam a geração seguinte. Na seleção assistida por marcadores foi adotada a estratégia de acasalamento seletivo, acasalando os melhores machos com as piores fêmeas, e vice-versa, entre os 20 genitores selecionados (dez machos e dez fêmeas). Essa estratégia foi escolhida face sua eficiência em aumentar o poder de detecção de QTL para a característica sobre a qual os indivíduos foram selecionados, maximizando a variabilidade genética na amostra, segundo afirmam Lander \& Botstein (1989) e Darvasi \& Soller (1992). Ela otimiza a dissimilaridade genética entre os genitores selecionados, favorecendo o mapeamento de QTL (Liu, 1998).

A seleção assistida por marcadores foi conduzida em diferentes tamanhos populacionais. Eles representavam distintas proporções da população experimental (inicial) disponível. Foram admitidos dez diferentes tamanhos de população (famílias), que representavam $5,10,15,20,25,30$, 35, 40, 45 e 50\% dos indivíduos disponíveis na população experimental. Desta forma, a partir das populações iniciais, compostas de 1.000 indivíduos cada, um número de 50, 100, 150, 200, 250, 300, 350, 400, 450 e 500 indivíduos foi mantido em cada geração sob MAS, oriundos de dez acasalamentos seletivos (uma fêmea/macho - melhores vs piores), resultando cada qual $5,10,15,20,25,30,35,40,45$ e 50 
descendentes, respectivamente. Logo, obtida a população inicial para cada genoma (nível de herdabilidade), foram praticadas dez seleções assistidas por marcadores.

A identificação de associações entre marcadores e QTL na seleção assistida por marcadores deu-se por meio do método da marca simples. Este método verifica a associação entre cada marcador e a característica de interesse. A análise de regressão linear entre os genótipos dos marcadores flanqueadores do QTL e os valores fenotípicos dos descendentes dos acasalamentos foi o teste estatístico utilizado no método. Adotou-se o nível de significância genômica de 5\% na regressão linear simples.

Para comparação dos diferentes tamanhos de população adotados na MAS foram estimados os valores fenotípicos médios em cada geração. Com base nesses valores, os tamanhos populacionais foram agrupados utilizando duas técnicas de estatística multivariada: o método de otimização de Tocher e o método hierárquico da ligação completa. $\mathrm{Na}$ aplicação dessas técnicas de agrupamento, os tamanhos populacionais foram considerados como tratamentos. As proporções de $5,10,15,20,25,30,35,40,45$ e $50 \%$ representavam os tratamentos $1,2,3,4,5,6,7,8,9$ e 10, respectivamente. Cada geração representou uma variável, totalizando 20 variáveis. Elas foram utilizadas com a finalidade de propor uma estrutura classificatória para formação de grupos similares entre os tamanhos populacionais.

Estas análises foram realizadas em cada nível de herdabilidade $(0,10 ; 0,40$ e 0,70$)$, utilizando o Sistema para Análises Estatísticas e Genéticas (SAEG), descrito por Ribeiro Junior \& Melo (2008).

\section{Resultados e Discussão}

As intensidades de seleção variaram de acordo com a proporção de indivíduos que foram mantidos no decorrer das gerações (Tabela 1) em relação à população inicial disponível, diferenciando-se pelo tamanho da família (número de descendentes/progênies por acasalamento).

Todos os processos de seleção partiram do mesmo valor fenotípico na população experimental $(10,00$ unidades), possibilitando comparações entre os tamanhos populacionais. A partir das primeiras gerações foram observados padrões de similaridades entre tamanhos amostrais específicos, estendendo-se até a $20^{0}$ a geração. Semelhanças no desempenho fenotípico foram obtidas para as intensidades de 5 e $10 \%, 15$ a $25 \%$ e entre 30 a $50 \%$. As populações com 50 e 100 indivíduos propiciaram os menores incrementos fenotípicos, visto que em amostras pequenas somente os QTL de grande efeito são passíveis de identificação. Para 150 a 250 descendentes, os ganhos

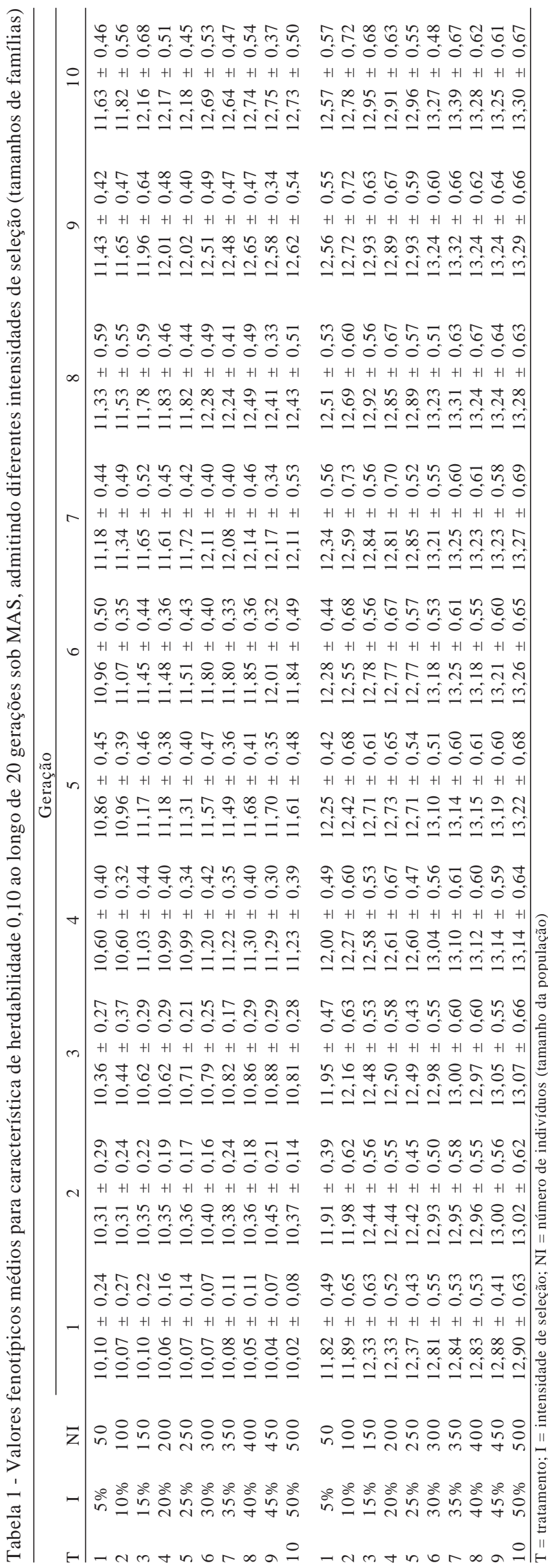

R. Bras. Zootec., v.39, n.12, p.2625-2631, 2010 
foram intermediários aos resultantes indicados pelas intensidades extremas consideradas. Já entre 300 e 500 indivíduos observou-se determinada correspondência nos ganhos fenotípicos durante todas as gerações, os quais foram superiores em comparação as menores intensidades.

O tamanho da população é um dos fatores fundamentais para se obterem resultados consistentes em trabalhos de mapeamento. De acordo com Young (1994) e Bhering \& Cruz (2008), amostras pequenas apresentarão provavelmente baixa resolução no mapeamento, dificultando a detecção de QTL de pequeno efeito. Esse tamanho limitado disponibiliza poucos genótipos para análise de QTL, reduzindo sua associação com os marcadores e, futuramente, sua utilização nas gerações subsequentes sob MAS.

O tamanho populacional adequado depende do tipo de população. Populações que aumentam a dissimilaridade genética entre seus genitores, a exemplo da resultante da estratégia seletiva de acasalamento ou populações $F_{2}$, requerem menores tamanhos para determinado poder de deteç̧ão de QTL. A vantagem na utilização desses genótipos é devido ao maior desequilíbrio de ligação encontrado em seus locus (Lannes et al., 2004). Todavia, o tamanho ideal, de acordo com o tipo e a estrutura genômica da população, ainda não está bem definido, devido à falta de padrão para análise de dados envolvendo mapeamento (Cruz, 2006).

A análise estatística multivariada de agrupamento foi aplicada utilizando-se os valores fenotípicos médios obtidos ao longo das 20 gerações, em que cada geração representou uma variável. Foram utilizados dois métodos de agrupamento: método de otimização de Tocher e método da ligação completa. Em ambos os métodos a distância euclideana média foi usada para quantificar as dissimilaridades entre os tratamentos (tamanhos populacionais).

Três grupos distintos são formados pelo método de Tocher (Tabela 2). No grupo 1 foram classificados os tamanhos amostrais de 150, 200 e 250 indivíduos. O segundo grupo foi formado pelas populações com 300 a 500 descendentes. Já o grupo 3 compreendeu as amostras com 50 e 100 indivíduos. Evidência-se, com base nos incrementos fenotípicos médios, a inferioridade do grupo 3 e a superioridade do grupo 2 .

O resultado do dendrograma estabelecido pelo método da ligação completa diverge em relação ao método de Tocher por não estabelecer um número ótimo de grupos, ilustrando apenas ramificações para inferências quanto aos padrões de similaridade (Figura 1). Entretanto, delimitações para formação de determinado número de grupos podem ser definidas, com base em exames visuais ou técnicas estatísticas. Neste trabalho, a linha de corte para estabelecer o número de grupos, bem como os tratamentos pertencentes,
Tabela 2 - Grupos, limite e distâncias obtidas entre os tratamentos (intensidades de seleção) pela aplicação do método de Tocher para herdabilidade de 0,10

\begin{tabular}{ccccc}
\hline $\begin{array}{c}\text { Número } \\
\text { do grupo }\end{array}$ & Limite $(\theta)$ & $\begin{array}{c}\text { Distância } \\
\text { obtida }\end{array}$ & $\begin{array}{c}\text { Número de } \\
\text { tratamentos }\end{array}$ & $\begin{array}{c}\text { Tratamentos } \\
\text { pertencentes }\end{array}$ \\
\hline 1 & 0,1697 & 0,03 & 2 & $3 ; 4$ \\
1 & 0,1697 & 0,05 & 3 & $3 ; 4 ; 5$ \\
2 & 0,1697 & 0,05 & 2 & $6 ; 7$ \\
2 & 0,1697 & 0,08 & 3 & $6 ; 7 ; 10$ \\
2 & 0,1697 & 0,07 & 4 & $6 ; 7 ; 10 ; 8$ \\
2 & 0,1697 & 0,08 & 5 & $6 ; 7 ; 10 ; 8 ; 9$ \\
3 & 0,1697 & 0,16 & 2 & $1 ; 2$ \\
\hline
\end{tabular}

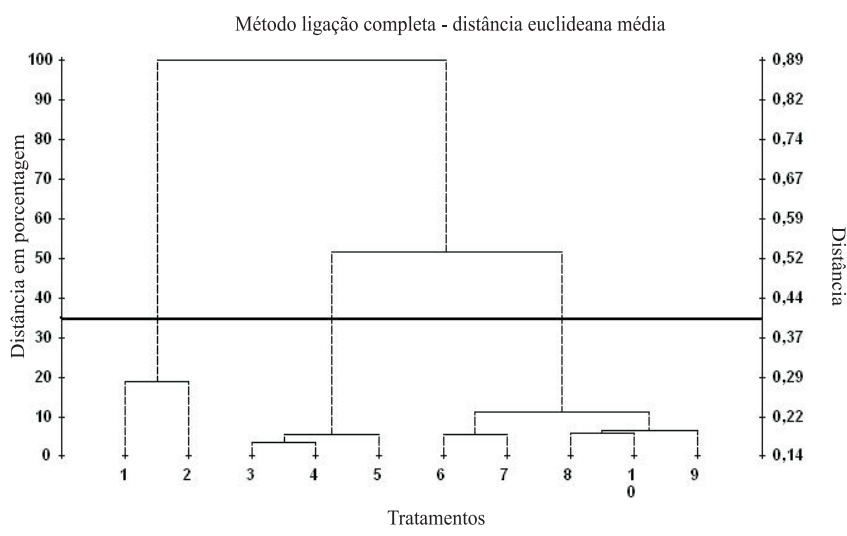

Figura 1 - Dendrograma do método da ligação completa pela análise de dez tratamentos (intensidades de seleção) para herdabilidade de 0,10.

foi determinada pelo número de grupos formados pelo método de Tocher. A distância em porcentagem de 35\% foi o nível adotado para o ponto de corte, mantendo o mesmo número de partições entre os dois métodos. Os resultados demonstraram equivalência entre os métodos de agrupamento, cujos grupos foram constituídos pelos mesmos tamanhos populacionais. As análises corroboraram as suposições feitas inicialmente, com base nas médias fenotípicas. A complementação advinda com as técnicas estatísticas implementou as inferências, proporcionando maior credibilidade aos resultados.

Nesta população experimental cuja característica é de baixa herdabilidade, manter 300 indivíduos sob MAS é suficiente para otimizar o poder de detecção de QTL. A eficiência nos progressos fenotípicos foi comparável entre os tamanhos populacionais de 300 a 500 descendentes. Desta forma, a seleção estratégica com base nos princípios da genotipagem seletiva favorece a manutenção de menores populações em pesquisas de mapeamento. Ela minimiza os custos com os processos de genotipagem, em prol do mesmo poder de detecção de locus quantitativos e, consequentemente, da otimização dos incrementos fenotípicos. 
Os tamanhos populacionais para a característica de média herdabilidade seguiram os mesmos padrões mencionados para a característica anterior (Tabela 3). Nas gerações iniciais, as respostas fenotípicas foram aumentadas para tamanhos amostrais iguais ou superiores a 250 indivíduos. Menores acréscimos foram identificados para as intensidades inferiores, especialmente para 50 descendentes. A partir das gerações intermediárias, as amostras entre 200 a 500 indivíduos proporcionaram resultados relativamente comparáveis. Os tamanhos com 50 e 100 descendentes mantiveram as divergências em analogia aos demais, apesar do declínio na magnitude da inferioridade dos ganhos fenotípicos ao longo das gerações.

Três grupos distintos são formados pelo método de Tocher (Tabela 4). No grupo 1 foram classificados os tamanhos amostrais de 250 a 500 indivíduos. No segundo grupo foram inseridas as populações com 150 e 200 descendentes. Já o grupo 3 compreendeu as amostras com 50 e 100 indivíduos. Evidencia-se, com base nos incrementos fenotípicos médios, a inferioridade do grupo 3 e a superioridade do grupo 1.

Novamente, à distância em porcentagem de 35\% foi admitida como ponto de corte, mantendo o mesmo número de partições entre os dois métodos. Os resultados sugeriram equivalência entre os métodos de agrupamento, cujos grupos foram constituídos pelos mesmos tamanhos populacionais (Figura 2).

Nesta população experimental com característica de média herdabilidade, manter 250 indivíduos é suficiente para otimizar o poder de detecção de QTL, face aos progressos fenotípicos comparáveis obtidos entre os tamanhos populacionais de 250 a 500 descendentes. A detecção de QTL está relacionada ao mecanismo de herança genética da característica e ao número de indivíduos genotipados, entre outros fatores (Mackay, 2001; Schuster \& Cruz, 2004). Em analogia a característica anterior, o maior vínculo entre o genótipo e o fenótipo para o caráter em questão favorece a manutenção de menores populações em pesquisas de mapeamento. As estimativas dos efeitos dos QTL na expressão desta característica serão mais fidedignas devido à maior acurácia proporcionada pela herdabilidade do caráter, reduzindo a participação do ambiente na determinação do fenótipo.

Nas gerações iniciais as respostas fenotípicas foram maximizadas para tamanhos populacionais com 250 a 500 indivíduos. Já os menores incrementos foram associados às intensidades com 50 e 100 descendentes. Entretanto, com gerações consecutivas sob seleção, a partir das gerações intermediárias as amostras envolvendo 150 a 500 indivíduos

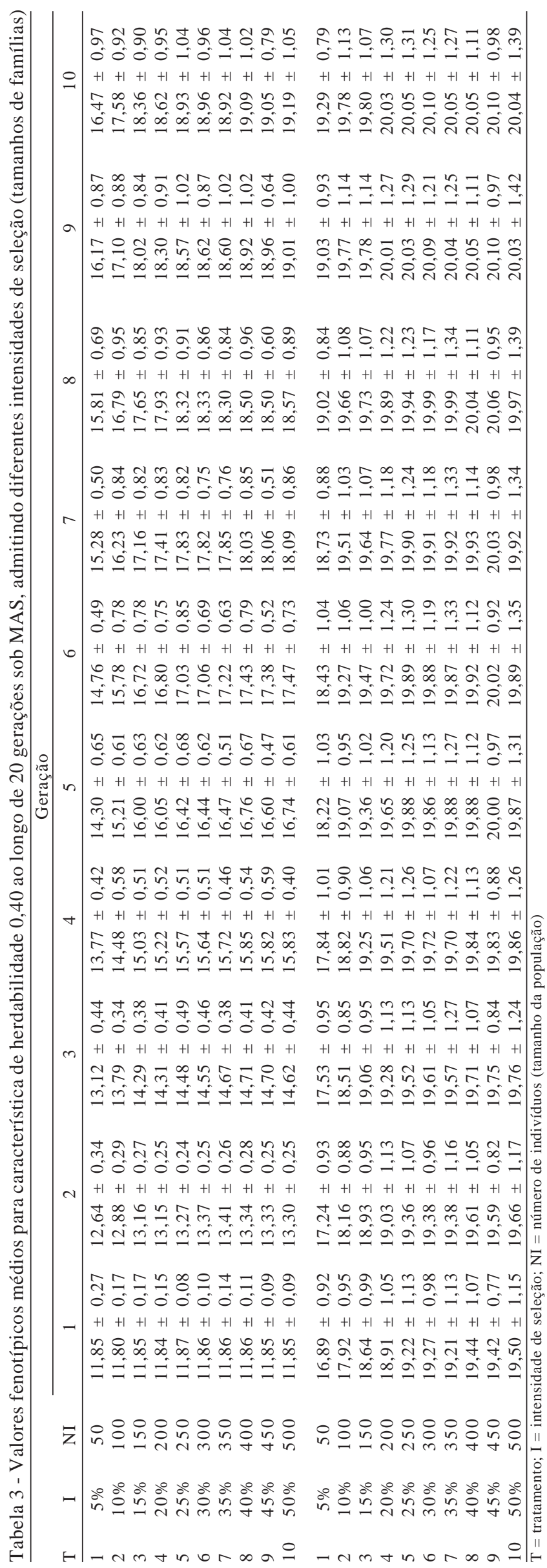

R. Bras. Zootec., v.39, n.12, p.2625-2631, 2010 
Tabela 4 - Grupos, limite e distâncias obtidas entre os tratamentos (intensidades de seleção) pela aplicação do método de Tocher para herdabilidade de 0,40

\begin{tabular}{ccccc}
\hline $\begin{array}{c}\text { Número } \\
\text { do grupo }\end{array}$ & Limite $(\theta)$ & $\begin{array}{c}\text { Distância } \\
\text { obtida }\end{array}$ & $\begin{array}{c}\text { Número de } \\
\text { tratamentos }\end{array}$ & $\begin{array}{c}\text { Tratamentos } \\
\text { pertencentes }\end{array}$ \\
\hline 1 & 0,4648 & 0,05 & 2 & $5 ; 6$ \\
1 & 0,4648 & 0,07 & 3 & $5 ; 6 ; 7$ \\
1 & 0,4648 & 0,17 & 4 & $5 ; 6 ; 7 ; 9$ \\
1 & 0,4648 & 0,15 & 5 & $5 ; 6 ; 7 ; 9 ; 8$ \\
1 & 0,4648 & 0,15 & 6 & $5 ; 6 ; 7 ; 9 ; 8 ; 10$ \\
2 & 0,4648 & 0,16 & 2 & $3 ; 4$ \\
3 & 0,4648 & 0,46 & 2 & $1 ; 2$ \\
\hline
\end{tabular}

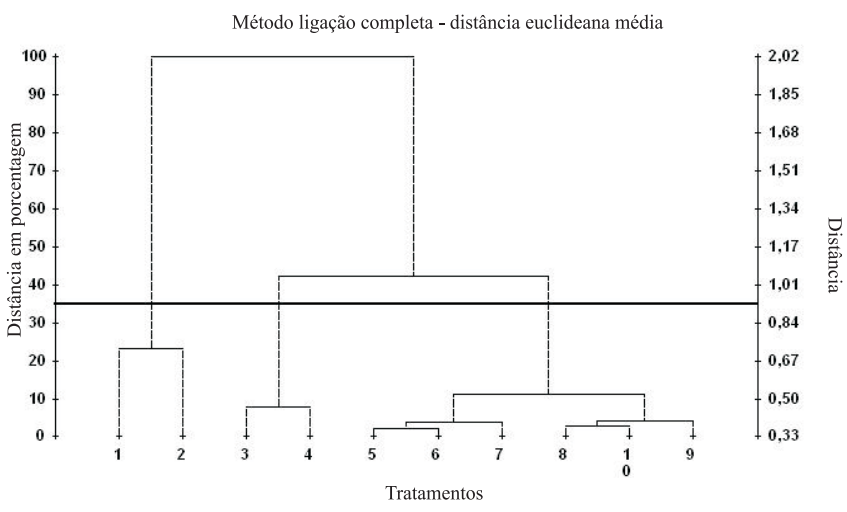

Figura 2 - Dendrograma do método da ligação completa pela análise de dez tratamentos (intensidades de seleção) para herdabilidade de 0,40 .

obtiveram resultados relativamente comparáveis. Essa equivalência foi otimizada nas gerações mais avançadas. As intensidades de 5 e $10 \%$ mantiveram ganhos fenotípicos inferiores frente às demais, com decréscimo na magnitude dessas diferenças ao longo das gerações (Tabela 5).

Os valores fenotípicos médios (Tabela 5) foram submetidos à análise de agrupamento. O método de Tocher indica a formação de três grupos similares (Tabela 6). O grupo 1 foi representado pelos tamanhos amostrais envolvendo 200 a 500 indivíduos. No segundo grupo incluíram-se as populações com 50 e 100 descendentes. Já o grupo 3 compreendeu apenas a amostra com 150 indivíduos. Evidencia-se, com base nos incrementos fenotípicos médios, a inferioridade do grupo 2 e a superioridade do grupo 1 . O método da ligação completa estabeleceu o dendrograma (Figura 3). O nível de corte foi instituído na distância de 35\%, para designar o mesmo número de grupos determinado pelo método de Tocher.

Novamente, os tratamentos pertencentes a cada partição coincidiram entre os dois métodos, prevalecendo este agrupamento. Embora os progressos fenotípicos demonstrassem similaridade entre as intensidades de 15 a $50 \%$ na maioria das gerações, os métodos foram sensíveis

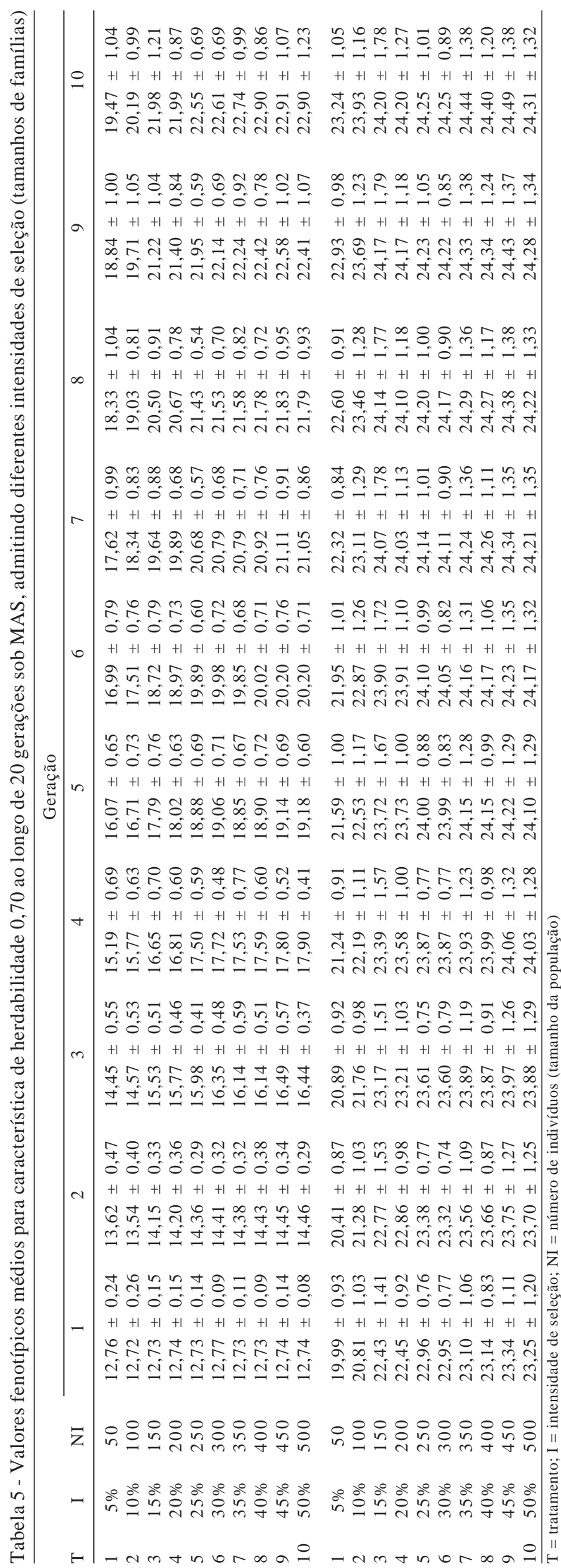

R. Bras. Zootec., v.39, n.12, p.2625-2631, 2010 
Tabela 6 - Grupos, limite e distâncias obtidas entre os tratamentos (intensidades de seleção) pela aplicação do método de Tocher para herdabilidade de 0,70

\begin{tabular}{ccccc}
\hline $\begin{array}{c}\text { Número } \\
\text { do grupo }\end{array}$ & Limite $(\theta)$ & $\begin{array}{c}\text { Distância } \\
\text { obtida }\end{array}$ & $\begin{array}{c}\text { Número de } \\
\text { tratamentos }\end{array}$ & $\begin{array}{c}\text { Tratamentos } \\
\text { pertencentes }\end{array}$ \\
\hline 1 & 0,7274 & 0,09 & 2 & $7 ; 8$ \\
1 & 0,7274 & 0,16 & 3 & $7 ; 8 ; 10$ \\
1 & 0,7274 & 0,15 & 4 & $7 ; 8 ; 10 ; 9$ \\
1 & 0,7274 & 0,20 & 5 & $7 ; 8 ; 10 ; 9 ; 6$ \\
1 & 0,7274 & 0,21 & 6 & $7 ; 8 ; 10 ; 9 ; 6 ; 5$ \\
1 & 0,7274 & 0,47 & 7 & $7 ; 8 ; 10 ; 9 ; 6 ; 5 ; 4$ \\
2 & 0,7274 & 0,72 & 2 & $1 ; 2$ \\
3 & 0,7274 & $* * * *$ & 1 & 3 \\
\hline
\end{tabular}

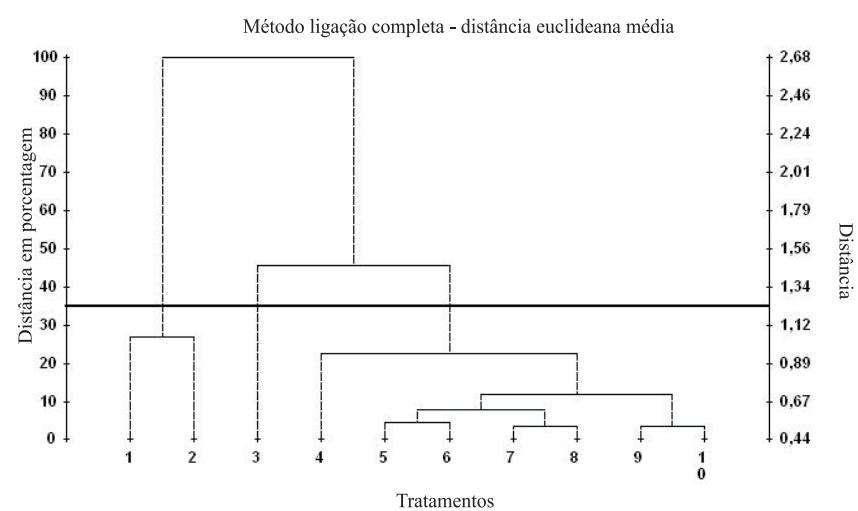

Figura 3 - Dendrograma do método da ligação completa pela análise de dez tratamentos (intensidades de seleção) para herdabilidade de 0,70 .

ao discriminar a amostra com 150 indivíduos das demais, face sua divergência nas gerações iniciais.

Na característica de alta herdabilidade a população sob seleção poderá apresentar tamanho ainda menor, em analogia às duas anteriores. Os resultados sugerem semelhanças entre os valores fenotípicos obtidos para as amostras com 200 a 500 indivíduos. Por representar um fator determinante na detecção de QTL, essa alta herdabilidade favorece maior identidade entre o genótipo e o fenótipo dos indivíduos, proporcionando maior acurácia na identificação e caracterização dos locus quantitativos.

\section{Conclusões}

A seleção estratégica acasalando os melhores e os piores genitores é eficiente quando se pretende reduzir o número de indivíduos requeridos na população para mapeamento de locus quantitativos. À medida que a magnitude da herdabilidade aumenta, menores tamanhos populacionais são requeridos para aumentar o poder de detecção de locus de interesse. Os métodos de Tocher e da ligação completa proporcionam partições entre os tamanhos populacionais semelhantes, implementando as inferências a cerca dos padrões de classificação.

\section{Agradecimentos}

À Universidade Federal de Viçosa (UFV) e ao Conselho Nacional de Desenvolvimento Científico e Tecnológico (CNPq), pelo apoio financeiro.

\section{Referências}

BHERING, L.L.; CRUZ, C.D. Tamanho de população ideal para mapeamento genético em famílias de irmãos completos. Pesquisa Agropecuária Brasileira, v.43, n.3, p.379-385, 2008.

CRUZ, E.M. Efeito da saturação e do tamanho de populações $F_{2}$ e de retrocruzamento sobre a acurácia do mapeamento genético. 2006. 119f. Tese (Doutorado em Genética e Melhoramento) - Universidade Federal de Viçosa, Viçosa, 2006.

DARVASI, A.; SOLLER, M. Selective genotyping for determination of linkage between a marker locus and a quantitative trait locus. Theoretical and Applied Genetics, v.85, n.2-3, p.353-359, 1992.

EUCLYDES, R.F. Uso do sistema para simulação Genesys na avaliação de métodos de seleção clássicos e associados a marcadores moleculares. 1996. 149f. Tese (Doutorado em Genética e Melhoramento) - Universidade Federal de Viçosa, Viçosa, 1996.

LANDER, E.S.; BOTSTEIN, D. Mapping Mendelian factors underlying quantitative traits using RFLP linkage maps. Genetics, v.121, n.1, p.185-199, 1989.

LANNES, S.D.; ZIMMER, P.D.; OLIVEIRA, A.C. et al. Regeneração in vitro de anteras de arroz irrigado (Oryza sativa L.) e mapeamento de QTL associado. Ciência Rural, v.34, n.5, p.1355-1362, 2004.

LIU, B.H. Statistical genomics: linkage, mapping and QTL analysis. Boca Raton: CRC Press, 1998. 611p.

MACKAY, T.F.C. The genetic architecture of quantitative traits Annual Review of Genetics, v.35, p.303-339, 2001

RIBEIRO JUNIOR, J.I.; MELO, A.L.P. Guia prático para utilização do SAEG. Viçosa, MG: Editora UFV, 2008. 288p.

SCHUSTER, I.; CRUZ, C.D. Estatística genômica aplicada a populações derivadas de cruzamentos controlados. Viçosa, MG: Editora UFV, 2004. 568p.

SILVA, K.M.; GUIMARÃES, S.E.F.; LOPES, P.S. et al. Mapeamento de locos de características quantitativas para desempenho no cromossomo 4 de suínos. Revista Brasileira de Zootecnia, v.38, n.3, p.474-479, 2009.

SILVA, M.V.G.B.; MARTINEZ, M.L.; TORRES, R.A. et al. Modelos aleatórios na estimação da localização de QTLs em famílias de meio-irmãos. Revista Brasileira de Zootecnia, v.34, n.1, p.66-75, 2005.

VAN DER BEEK, S.; VAN ARENDONK, J.A.M.; GROEN, A.F. Power of two and three-generation QTL, mapping experiments in an outbred population containing full-sib or half-sib families. Theoretical and Applied Genetics, v.91, n.6-7, p.1115-1124, 1995.

ZHU, J.J.; LILlEHOJ, H.S.; CHENG, H.H. et al. Screening for highly heterozygous chickens in outbred commercial broiler lines for QTL mapping to increase detection power. Poultry Science, v.80, n.1, p.6-12, 2001.

YOUNG, N.D. Constructing a plant genetic linkage map with DNA makers. In: PHILLIPS, R.L.; VASIL, I.K. (Eds.) DNA: based markers in plants. Dordrecht: Kluwer Academic Publisher, 1994. p.31-47. 